\title{
The Effect of Walking Exercise and Consumption of Steeping Chamomile Flowers (Matricaria recutita) on Depression in the Elderly in Langsa City
}

\author{
T. Iskandar Faisal ${ }^{1 *}$, Nuswatul Khaira ${ }^{1}$, Nora Veri $^{2}$, Magfirah Magfirah $^{2}$, Dewita Dewita $^{2}$, Alchalidi Alchalidi $^{2}$, Yuni Sari $^{3}$ \\ ${ }^{1}$ Department of Nursing, Polytechnic of Health, Ministry of Health, Aceh, Indonesia; ${ }^{2}$ Department of Midwifery, Ministry of Health- \\ Polytechnic of Langsa, Aceh, Indonesia; ${ }^{3}$ Department of Midwifery, Ministry of Health, Polytechnic of Health, Aceh, Indonesia
}

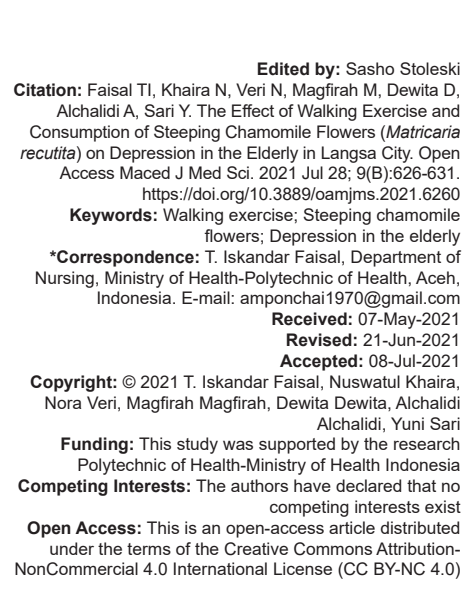

\section{Introduction}

The composition of the elderly population is increasing rapidly in almost every part of the world. The same thing happened in Indonesia, the Central Bureau of Statistics (2015) reported that the elderly population in 2010 was 18.1 million and increased to 22,041,000 in 2015. Meanwhile, in 2030 and 2035, the elderly population in Indonesia is predicted to increase, respectively to 40.95 million and 48.19 million people. The aging process is accompanied by a decrease in physical, psychological, and social conditions that interact with each other, which tends to have the potential to cause health problems in general and mental health in particular for the elderly. one of the health problems in the elderly is depression. Depression is a leading cause of disability worldwide and a significant contributor to any disease's overall global burden [1]. The World Health Organization estimates that $\sim 350$ million people suffer from depression, while more than 800,000 people die from suicide each year [2]. In the elderly, depression can cause suffering: cognitive impairment, family disorders, and increased mortality [3]. Depression in tension must be handled properly. Otherwise, it will hurt the quality of life of the elderly and increase the risk of death. The harmful effects of depression include physical illness, worsening physical illness, prolonged healing after surgery or suffering from illness, cognitive impairment, increased suicide rates, or deadly diseases. Depression decreases the quality of life and increases the risk of suicide [4], Likewise depression reduces the degree of health and social care, including the use of unscheduled care [5]. Because the consequences of loneliness and depression are closely related to the elderly and 
loneliness is a risk factor for depression [6], [7]. About $80 \%$ of depressed elderly who undergo treatment can recover completely and enjoy their life, but $90 \%$ of those who are depressed ignore and refuse treatment for mental disorders [8] While the emergence of conventional drug therapies for anxiety and depression has simplified their treatment, many of the population is either untreated or rejecting conventional therapy for financial, cultural, or personal reasons [9]. Many people seek complementary and alternative medicine for their symptoms [10]. Therefore, the identification of inexpensive and effective alternative therapies for anxiety and depression is relevant to public health [11]. Chamomile (Matricaria recutita) is one of the most widely used herbal medicines in the world. Chamomile (M. recutita heals skin lesions in colostomy patients and is beneficial for general anxiety disorders (GAD) and anxiolytic activity in patients with mild to moderate GAD). The chemical compounds of this plant are as follows apigenin, apigenin-7-O-glucoside, caffeic acid, chlorogenic acid, luteolin, and luteolin-7-O-glucoside, terpene bisabolol, farnesene, chamazulene, flavonoids (including apigenin) quercetin, patuletin, and luteolin), and coumarin [12], [13]. One of the efforts to reduce stress in the elderly is by doing walking exercises. Sports walking is a physical activity that various groups easily carry out. For the elderly, it is highly recommended to do physical activities such as walking in the morning to fill their spare time. Regular exercise can be an effective way to improve blood circulation.

The morning walk has a dynamic movement, is easy to do, creates a feeling of joy and enthusiasm, and is a low burden. This sports activity helps the body stay in shape because it can train bones to be strong, encourage the heart to work optimally, and eliminate free radicals that roam the body. This morning walk can shape and correct attitudes and movements, slow down the degeneration process due to changes in age, and facilitate the adjustment of physical health, especially cardiovascular health, in the adaptation of elderly life. considering the importance of walking exercise and steeping chamomile flowers to the health of the elderly. Therefore, this study aims to analyze walking and consumption of chamomile ( $M$. recutita) flower infusions on depression in the elderly in Langsa City.

\section{Methods}

This study used a quasi-experimental design with a pretest-posttest control group design. This research was conducted from September to December in Karang Anyar Village, Kec. Langsa Baro Langsa City. This study population was all elderly who met the inclusion criteria, namely: aged 60-74 years, able to walk, not to suffer from arthritis (arthritis), not using walking aids, not experiencing vision problems, not experiencing hearing loss, not participating in gymnastics. Routine, do not suffer from chronic diseases (heart disease, hypertension, diabetes mellitus, and mental illness). The sample size of the study was calculated using the formula for the sample size for experimental research from Federer, namely, $(t-1)(r-1) \geq 15)$

$$
\begin{aligned}
& (t-1)(r-1) \geq 15 \\
& (4-1)(r-1) \geq 15 \\
& 3(r-1) \geq 15 \\
& 3 r-3 \geq 15 \\
& 3 r \geq 18 \\
& r \geq 6
\end{aligned}
$$$$
\mathrm{t} \text { : many treatment groups }
$$$$
\text { r: number of replications. }
$$

In this study, the number of groups $=4$, the minimum number of replications $=6$. The total sample was 24 older adults. In this study, the elderly were divided into three groups. The control group is the walking exercise treatment group, the chamomile flower is the infusion treatment group, the chamomile flower has the infusion treatment group, and the walking exercise group was essential. Depression data were measured using the Geriatric Depression Scale (GDS) questionnaire and observed twice, namely at the pretest and post-test. Data collection techniques in this study were interviews and observations using the GDS questionnaire instrument, which was carried out twice, namely before treatment and after treatment in four groups, namely the control group, the walking exercise group, the chamomile flower consumption group, and the combination group of walking and consumption sports chamomile flowers. In this study, the data analysis technique was carried out in three counting stages. The successive stages are the first, the normality test of the sample data with the Shapiro-Wilk test. Second, the homogeneity test of variance with the Levene test compares the GDS scores between the pretest and post-test data in the control and treatment groups using the paired t-test. Third, the one-way analysis of variance test to see the effect of the intervention on depression. All calculations were carried out with the aid of the SPSS for Windows 20.0 software.

\section{Results}

\section{Parametric prerequisite test results}

This stage is carried out by testing the comparison of the average score of the GDS in the control group and the walking treatment group. Then the treatment of chamomile tea consumption and a 
combination of walking with consumption of chamomile tea used the paired t-test. Before testing the paired t-test, testing the underlying assumptions of the parametric test, namely the assumption of normality and the homogeneity test. The normality test was performed using the Shapiro-Wilk test. The assumption of normality is said to be fulfilled if the calculated $p$-value is greater than $\alpha=0.05$.

Table 1: Normality assumption test

\begin{tabular}{lllll}
\hline Score GDS & Data & Coefficient & p-value & Description \\
\hline Control & Pretest & 0.846 & 0.145 & Normal \\
& Posttest & 0.827 & 0.101 & Normal \\
KP1 & Pretest & 0.856 & 0.177 & Normal \\
& Posttest & 0.876 & 0.252 & Normal \\
KP2 & Pretest & 0.823 & 0.094 & Normal \\
& Posttest & 0.884 & 0.287 & Normal \\
KP3 & Pretest & 0.844 & 0.140 & Normal \\
& Posttest & 0.704 & 0.070 & Normal \\
\hline Information: KP1 (walking practice), KP2 (consumption of chamomile tea) and KP3 (walking and \\
consumption of chamomile tea), GDS: Geriatric depression scale.
\end{tabular}

Based on the Tables 1 and 2, testing the assumption of homogeneity of the various GDS scores in all groups obtained a $\mathrm{p}$-value more significant than $\alpha=0.05$ ( $p>0.05)$, which indicates that the assumption of homogeneity of the various depression scores using the GDS instrument has been fulfilled.

Table 2: Variety homogeneity test

\begin{tabular}{llll}
\hline Score GDS & Coefficient & p-value & Description \\
\hline Control & 0.002 & 0.967 & Homogen \\
KP1 & 1.193 & 0.300 & Homogen \\
KP2 & 0.860 & 0.376 & Homogen \\
KP3 & 1.194 & 0.300 & Homogen \\
\hline Source: Primary Data (2019). Information: KP1 (walking practice), KP2 (consumption of chamomile tea) \\
and KP3 (walking and consumption of chamomile tea), GDS: Geriatric depression scale.
\end{tabular}

The difference in average depression in the elderly before and after treatment

The following is the difference in the average GDS between the pretest and posttest in each group using the Paired t-test.

Table 3: Differences in the average score of depression before and after treatment in the respondent group

\begin{tabular}{lllll}
\hline Respondence Group & \multicolumn{2}{l}{ Mean \pm SD } & Difference in average & p-value \\
\cline { 2 - 3 } & Pre-test & Post-test & & \\
\hline Control & $7.67 \pm 6.62$ & $7.33 \pm 6.15$ & 0.33 & 0.661 \\
KP1 & $7.33 \pm 4.55$ & $4.00 \pm 3.35$ & 3.33 & 0.025 \\
KP2 & $5.83 \pm 4.40$ & $2.83 \pm 2.32$ & 3.00 & 0.037 \\
KP3 & $8.33 \pm 3.67$ & $5.00 \pm 4.82$ & 3.33 & 0.017 \\
\hline Sonnn
\end{tabular}

KP1 (walking practice), KP2 (consmption of chamomile

tea) and KP3 (walking and consumption of chamomile tea).

Table 3 shows a difference in the mean GDS in the respondent group. There is an average decrease in all groups of respondents. The lowest pretest GDS score was found in the KP2 group, namely, 5.83, and the highest in the KP3 group, namely 8.33. Meanwhile, the lowest post-test measurement was in the KP2 group, namely, 2.83, and the highest in the control group, 7.33. In the control group, the elderly GDS score at pretest was 7.67 and decreased at post-test to 7.33. The difference in the reduction is 0.33 . However, statistically obtained a p-value of 0.661 ( $p>0.05$ ), which means that there was no significant decrease in the GDS score in the control group. The following is the difference in the average depression score of the GDS can be illustrated in the Figure 1 as follows:

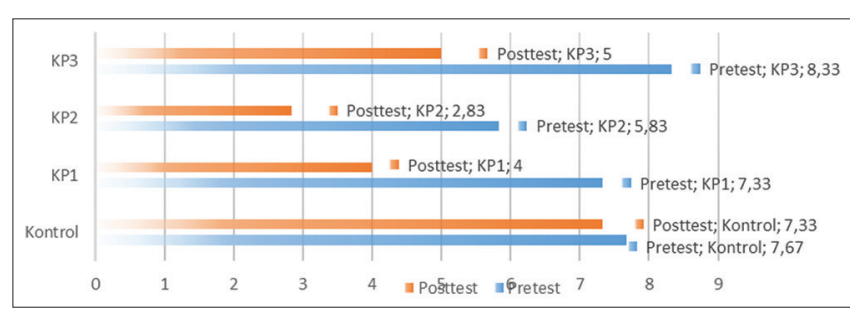

Figure 1: Differences in the mean GDS depression score of the elderly before and after treatment in the respondent group were essential

The Figure 1 illustrates the average GDS score in each group at the pretest and post-test. There is a decrease in the GDS score at post-test compared to pretest.

The effect of walking on depression in the elderly

In Table 3, it can be seen that the GDS depression score of the walking treatment group (KP1) at pretest was $7.33 \pm 4.55$, and at post-test, it fell to $4.00 \pm 3.35$. Descriptively, there was a difference in the mean score of GDS depression between the pretest and post-test, where there was a decrease in the GDS depression score after walking treatment by 3.33. The $p$-value for the decrease in the GDS score is $0.025(p \leq \alpha)$, which means that statistically, walking can reduce the GDS depression score significantly/ significantly.

\section{Effect of chamomile tea consumption on} depression in the elderly

In Table 3, the GDS score for the treatment group consumption of chamomile tea (KP2) at pretest was $5.83 \pm 4.40$, and at post-test, it fell to $2.83 \pm 2.32$. Descriptively there is a difference in the mean score of the GDS between the pretest and post-test where there is a decrease in the GDS depression score after the treatment of chamomile tea consumption by 3.00 . The table also shows that the $p$-value for a decrease in the GDS depression score is 0.037 ( $p \leq \alpha)$, which means that statistically, chamomile tea consumption can significantly reduce the GDS score.

The effect of combined walking and consumption of chamomile tea on elderly depression

In Table 3, the GDS score for the combination treatment group of walking and consumption of chamomile tea (KP3) at pretest was $8.33 \pm 3.67$ post-test, it fell to $5.00 \pm 4.82$. Descriptively there is a difference in the mean score of the GDS between the pre-test and post-test where there is a decrease in the GDS score after the treatment of chamomile tea consumption by 3.33 . The table also shows the $p$-value for the decrease in the GDS depression score of 0.017 $(p \leq \alpha)$, which means that statistically the combination 
treatment of walking and consumption of chamomile tea can significantly reduce the GDS score.

\section{Least significant difference (LSD) post- hoc test results}

The post-hoc LSD test is a follow-up test that assesses the existence of significant differences between groups with an equal number of samples. The results of the post-hoc LSD test for the GDS score between groups of respondents are presented in the following table:

From Table 4, it can be seen that there is a significant difference in the GDS score between the control group and the KP1 and KP2 groups with a $p$-value of 0.038 ( $p \leq 0.05)$. The control with KP2 was not significantly different with $p$-value 0.063 $(p>0.05)$. This means that the difference in the GDS score is only found in the walking treatment group and the combination group walking and consumption of chamomile tea. Furthermore, KP1 and KP2 with a p-value of $0.808(p>0.05)$ and KP1 and KP3 with a $p$-value of $1.000(p>0.05)$ and KP2 and KP3 with a $p$-value of $0.808(p>0.05)$ which means that the three treatments have the same ability to reduce the GDS score.

Table 4: Results of post-hoc LSD test for GDS depression scores among groups of respondents

\begin{tabular}{llll}
\hline Respondent group & & Difference in average & $\mathrm{p}^{*}$ \\
\hline Control & KP1 & 3.00000 & 0.038 \\
& KP2 & 2.66667 & 0.063 \\
& KP3 & 3.00000 & 0.038 \\
KP1 & KP2 & -0.33333 & 0.808 \\
& KP3 & 0.00000 & 1.000 \\
KP2 & KP3 & 0.33333 & 0.808 \\
\hline Source: Post-hoc LSD (Less Square Differences), Information: KP1 (treatment group walking), KP2
\end{tabular}

(reatment group consumption of chamomile tea), KP3 (treatment group combination of walking an consumption of chamomile tea), GDS: Geriatric depression scale.

\section{Discussion}

The results of this study indicate that walking can reduce the GDS score. Significantly with a $p$-value of 0.025 . This study indicates that the consumption of chamomile tea can significantly reduce the GDS depression score in the elderly with a $p$-value of 0.037 . This study showed that the combination of walking and consumption of chamomile tea was able to significantly reduce the GDS depression score with a $p$-value of 0.017 . When viewed from the $p$-value, the treatment group showed the most significant decrease in the GDS score than the other two treatment groups, namely, walking and chamomile tea consumption. This is thought to be because walking with chamomile tea consumption can provide the most practical effect in reducing the GDS depression score in the elderly. To the best of the authors' knowledge, studies have not been carried out that combine walking with chamomile flowers simultaneously. So far, much research on the effects of chamomile flowers and physical exercise independently. Exercise walking has effectiveness in reducing depression in the elderly.Exercise walking can be done by the elderly to activate the endorphin hormone so that the elderly feel happy and make them more confident regarding aspects of quality of life. The elderly who have poor physical quality will undoubtedly experience various obstacles in carrying out their duties and work daily. Many physical obstacles will be experienced if good physical qualities do not support them. Therefore, it is very reasonable for the elderly to regularly carry out physical coaching and systematically-sports training for the elderly aims to improve physical fitness. Physical fitness in the elderly is fitness related to health, namely heart, heart, blood circulation, muscle strength, and joint flexibility. To obtain good physical fitness, they must train all the essential physical fitness components: heartendurance, blood circulation and respiration, muscle endurance, muscle strength, and body flexibility. Family support in aerobic exercise and walking in the elderly can reduce symptoms of depression [14]. involvement in physical activity with general health conditions can reduce the incidence of depression in the elderly [15], [16]. Physical activity can improve mental and clinical conditions in older adults who experience depression. Physical activity stimulates cognitive function, memory, and concentration, increases self-esteem, improves the quality of life, and helps lower scores indicating anxiety and depression [17], [18]. A community-based study conducted on an elderly population reports that depression is the most common mental health disorder in later life [19].

Although old age is not always a time of sadness and depression, some older people face challenges that are difficult to deal with effectively and experience distress, anxiety, demoralization, and loneliness. Often, the clinical picture of depression in old age is masked by memory difficulties with symptoms of distress and anxiety; However, this problem is secondary to depression [20], [21]. The use of chamomile as an herbal medicine has been around since ancient Greece and Rome. Chamomile ( $M$. recutita) has been used as a traditional herbal medicine for its calming effect. Other chamomile varieties have been used to treat symptoms of depression and anxiety, including Arvensis and Tanacetum parthenium d, and C. frustum [22], [23]. Chamomile may have a clinically significant antidepressant activity that occurs in addition to the anxiolytic activity observed previously [24]. Chamomile tea may be recommended for postpartum women as a different approach to reducing depression and sleep quality problems [25]. Chamomile oil decreases the analgesic requirements of knee osteoarthritis patients. 
Moreover, it may show some beneficial effects on physical function and patient stiffness [26]. Many of the respondents to the warm chamomile intervention admitted that after drinking warm chamomile tea, the pain or stiffness in the legs decreased so that the need for sleep could increase. This is because chamomile has a mild sedative effect. The chemical apigenin in chamomile will bind to benzodiazepine receptors in the central nervous system and work by stimulating the brain to relax muscles and stimulate drowsiness. Walking, consumption of chamomile tea and a combination of the two have the same ability to reduce the GDS score in the elderly in Langsa city.

\section{Conclusion}

There is a difference in the average score of the pretest and posttest GDS in the control group, treatment group 1 (walking), treatment group 2 (consumption of chamomile tea), and treatment group 3 (combination of walking and consumption of chamomile flowers). Walking can reduce the GDS depression score in the elderly. Consumption of chamomile flowers can reduce the GDS depression score in the elderly. The combination of walking and consumption of chamomileflowers can reduce the GDS depression score in the elderly The three treatment groups (walking, consumption of chamomile flowers and a combination of both have the same ability to reduce the GDS score in the elderly.

\section{References}

1. Ferrari AJ, Charlson FJ, Norman RE, Patten SB, Freedman G, Murray $\mathrm{CJ}$, et al. Burden of depressive disorders by country, sex, age, and year: Findings from the global burden of disease study 2010. PLoS Med. 2013;10(11):e1001547. https://doi:10.1371/ journal.pmed.1001547 PMid:24223526

2. World Health Organization. Media Centre Depression. Geneva: World Health Organization; 2016. Available from: http://www. who.int/mediacentre/factsheets/fs369/en. [Last accessed on 2021 April 14]

3. Alexopoulos GS. Depression in the elderly. Lancet. 2005;365(9475):1961-70. https://doi:10.1016/S0140-6736(05) 66665-2

PMid: 15936426

4. Manthorpe J, lliffe S. Suicide among older people. Nurs Older People. 2006;17(10):25-9. https://doi:10.7748/ nop2006.01.17.10.25.c2404 PMid:16445224

5. Dickens C, Katon W, Blakemore A, Khara A, McGowan L, Tomenson $\mathrm{B}$, et al. Does depression predict the use of urgent and unscheduled care by people with long term conditions? A systematic review with meta-analysis. J Psychosom Res. 2012;73(5):334-42. https://doi:10.1016/j. jpsychores.2012.08.018 PMid:23062805

6. Heikkinen RL, Kauppinen M. Depressive symptoms in late life: A 10-year follow-up. Arch Gerontol Geriatr. 2004;38(3):239-50. https://doi:10.1016/j.archger.2003.10.004

\section{PMid:15066310}

7. Burholt V, Scharf T. Poor health and loneliness in later life: The role of depressive symptoms, social resources, and rural environments. J Gerontol B Psychol Sci Soc Sci. 2014;69(2):31124. https://doi:10.1093/geronb/gbt121 PMid:24326076

8. Casey DA. Depression in the elderly: A review and update. Asia Pac Psychiatry. 2012;4(3):160-7.

9. Wang PS, Lane M, Olfson M, Pincus HA, Wells KB, Kessler RC Twelve-month use of mental health services in the United States: Results from the national comorbidity survey replication. Arch Gen Psychiatry. 2005;62(6):629-40. https://doi:10.1001/ archpsyc.62.6.629 PMid: 15939840

10. Barnes PM, Powell-Griner E, McFann K, Nahin RL. Complementary and alternative medicine use among adults: United States, 2002. Adv Data. 2004;343:1-19. PMid: 15188733

11. Givens JL, Houston TK, Van Voorhees BW, Ford DE, Cooper LA. Ethnicity and preferences for depression treatment. Gen Hosp Psychiatry. 2007;29(3):182-91. https://doi:10.1016/j. genhosppsych.2006.11.002 PMid:17484934

12. Gosztola B, Sárosi S, Németh E. Variability of the essential oil content and composition of chamomile (Matricaria recutita L.) affected by weather conditions. Nat Prod Commun. 2010;5(3):465-70. PMid:20420329

13. Orav A, Raal A, Arak E. Content and composition of the essential oil of Chamomilla recutita (L.) Rauschert from some European countries. Nat Prod Res. 2010;24(1):48-55. https:// doi:10.1080/14786410802560690

PMid:20013472

14. Penninx BW, Guralnik JM, Ferrucci L, Simonsick EM, Deeg DJ, Wallace RB. Depressive symptoms and physical decline in community-dwelling older persons. JAMA. 1998;279(21):17206. https://doi:10.1001/jama.279.21.1720 PMid:9624025

15. Chatton A, Kayser B. Self-reported health, physical activity and socio-economic status of middle-aged and elderly participants to a popular road running race in Switzerland: Better off than the general population? Swiss Med Wkly. 2013;143:w13710. https://doi:10.4414/smw.2013.13710

PMid:23296994

16. Fortes $\mathrm{C}$, Mastroeni $\mathrm{S}$, Sperati $\mathrm{A}$, Pacifici $\mathrm{R}$, Zuccaro $\mathrm{P}$ Francesco $F$, et al. Walking four times weekly for at least $15 \mathrm{~min}$ is associated with longevity in a cohort of very elderly people. Maturitas. 2013;74(3):246-51. https://doi:10.1016/j. maturitas.2012.12.001 PMid:23280132

17. Stella F, Gobbi S, Corazza DJ, Costa JL. Depressão no idoso: Diagnóstico, tratamento e benefícios da atividade física. Motriz Rev Educ Fís. 2002;8(3):91-8.

18. Cheik NC, Reis IT, Heredia RA, de Lourdes Ventura M, Tufik S, Antunes HK, et al. Efeitos do exercício físico e da atividade física na depressão e ansiedade em indivíduos idosos. RBCM. 2003;11(3):45-52. 
19. Sivertsen H, Bjørkløf GH, Engedal K, Selbæk G, Helvik AS. Depression and quality of life in older persons: A review. Dement Geriatr Cogn Disord. 2015;40(5-6):311-39. https:// doi:10.1159/000437299

\section{PMid:26360014}

20. Lôo H, Gallarda T, Fabre I, Olié JP. Depression and aging. Bull Acad Natl Med. 2004;188(6):999-1007.

PMid: 15651428

21. Blazer DG. Depression in late life: Review and commentary. J Gerontol A Biol Sci Med Sci. 2003;58(3):249-65. https:/l doi:10.1093/gerona/58.3.m249

PMid:12634292

22. Manganelli RE, Tomei PE. Ethnopharmacobotanical studies of the Tuscan Archipelago. J Ethnopharmacol. 1999;65(3):181202. https://doi:10.1016/s0378-8741(98)00177-9 PMid:10404416

23. Vázquez FM, Suarez MA, Pérez A. Medicinal plants used in the Barros Area, Badajoz Province, Spain. J Ethnopharmacol.
1997;55(2):81-5. https://doi:10.1016/s0378-8741(96)01491-2 PMid:9032619

24. Amsterdam JD, Shults J, Soeller I, Mao JJ, Rockwell K, Newberg AB. Chamomile (Matricaria recutita) may provide antidepressant activity in anxious, depressed humans: An exploratory study. Altern Ther Health Med. 2012;18(5):44-9. PMid:22894890

25. Chang $\mathrm{SM}$, Chen $\mathrm{CH}$. Effects of an intervention with drinking chamomile tea on sleep quality and depression in sleep disturbed postnatal women: a randomized controlled trial. J Adv Nurs. 2016;72(2):306-15. https://doi:10.1111/jan.12836 PMid:26483209

26. Shoara R, Hashempur MH, Ashraf A, Salehi A, Dehshahri S, Habibagahi Z. Efficacy and safety of topical Matricaria chamomilla L. (chamomile) oil for knee osteoarthritis: A randomized controlled clinical trial. Complement Ther Clin Pract. 2015;21(3):181-7. https://doi:10.1016/j.ctcp.2015.06.003 PMid:26256137 